
$\$$ Research Square
Preprints are preliminary reports that have not undergone peer review.
They should not be considered conclusive, used to inform clinical practice,
or referenced by the media as validated information.

\title{
Clinical Efficacy of Radiotherapy Combined with Surgery for Locally Advanced Gastric Signet-Ring-Cell Carcinoma: A SEER Database Analysis
}

\author{
Xiaohan Lin \\ First Affiliated Hospital of Fujian Medical University \\ Biyu Chen \\ First Affiliated Hospital of Fujian Medical University \\ Wei Zheng \\ First Affiliated Hospital of Fujian Medical University \\ Shugang Yang \\ First Affiliated Hospital of Fujian Medical University \\ Guangwei Zhu \\ First Affiliated Hospital of Fujian Medical University \\ Jinzhou Wang \\ First Affiliated Hospital of Fujian Medical University \\ Yongjian Huang \\ First Affiliated Hospital of Fujian Medical University \\ Jianxin Ye ( $\nabla$ yejianxin@mail.fjmu.edu.cn) \\ First Affiliated Hospital of Fujian Medical University https://orcid.org/0000-0002-6118-8583
}

Research

Keywords: Gastric signet-ring-cell carcinoma, Radiotherapy, Surgical therapy, Clinical efficacy

Posted Date: November 1st, 2021

DOI: https://doi.org/10.21203/rs.3.rs-1022533/v1

License: (c) (i) This work is licensed under a Creative Commons Attribution 4.0 International License. Read Full License 


\section{Abstract}

Background: The objective of this study was to assess the clinical efficacy of radiotherapy combined with surgery for locally advanced gastric signetring-cell carcinoma (GSRCC).

Methods: Clinical data of patients with locally advanced GSRCC diagnosed by postoperative pathology from 2000-2016 were collected from the US Surveillance, Epidemiology and End Results (SEER) database. All the enrolled patients were divided into three groups according to treatment type: surgery alone ( $\mathrm{S} ; N=727$ ), surgery with preoperative radiotherapy (RT+S; $N=138$ ), surgery with postoperative radiotherapy ( $\mathrm{S}+\mathrm{RT} ; N=548)$.

Results: The median overall survival (OS) time in S, RT+S and S+RT group was 19, 26 and 33 months, respectively; the overall survival (OS) rate was $19.5 \%, 26.9 \%$ and $34.0 \%$, respectively; the median cancer-specific survival (CSS) time was 29,31 and 43 months, respectively; and the CSS rate was $32,4 \%, 35.3 \%$ and $43.6 \%$, respectively. After performing propensity score matching (PSM), it was found that the OS rate was significantly lower in S group than in $R T+S$ or $S+R T$ group (all $P<0.05)$ and the CSS rate was lower in the $S A$ group than in the $S+R T$ group $(P<0.0001)$ while there was no significant difference between $S$ and RT+S groups. The OS and CSS were not significantly different between RT+S and S+RT groups. Cox multivariate analysis showed that radiotherapy was an independent prognostic factor for OS and CSS of locally advanced GSRCC.

Conclusions: Compared to surgery alone, surgery combined with preoperative or postoperative radiotherapy is beneficial to the long-term survival of patients with locally advanced GSRCC.

\section{Background}

Gastric cancer (GC) is one of the most frequently occurring digestive tract cancers and ranks the fifth among malignant tumors and the fourth in the cancer-related deaths [1]. There are several grading systems for GC based on the morphological structures, biological behaviors and molecular mechanisms. At present, there are three main classification systems for GC which are Bormann classification, Lauren classification and World Health Organization (WHO) classification. Signet-ring-cell carcinoma (SRCC) is one of the WHO classifications, microscopically characteristic of a large amount of mucus in the cancer cells that pushes the nucleus to the side of the cell. The whole cell is signet ring-like and its malignancy is higher than that of extracellular mucus [2].

In recent years, epidemiological investigations have shown that the incidence of gastric signet-ring-cell carcinoma (GSRCC) is increasing yearly [3]. Because of the lack of typical clinical symptoms and suitable disease biomarkers, pathological mechanisms and precancerous lesions are unclarified [4]. Besides, the early diagnosis rate remains low and most patients are first diagnosed in advanced stages $[5,6]$. Previous studies have shown that compared to non-GSRCC, advanced GSRCCs are more aggressive, with a higher rate of lymph node metastasis and peritoneal implantation [7] being the most common cause of recurrence. Radiotherapy, add-on therapy to surgery, has been successfully used in the treatment of colorectal cancer, breast cancer, esophageal cancer and other malignant tumors with a high recurrence rate. Currently, much attention has been focused on the role of radiotherapy in the treatment of GC.

However, the effectiveness for patients with GSRCC remains disputed $[8,9]$. This study aimed to evaluate the efficacy of surgery combined with radiotherapy for locally advanced GSRCC using population-based data from the Surveillance, Epidemiology and End Results (SEER) program.

\section{Methods}

\section{Study population}

All data of enrolled patients were extracted from the SEER database (https://seer.cancer.gov/) using the SEER*stat software (version 8.3.8). The postoperative pathologic stage was classified based on the American Joint Committee on Cancer (AJCC) staging, seventh edition. The inclusion criteria were as follows: 1) Patients diagnosed between January 1, 2000 and December 31, 2016; 2) Patients who underwent radical surgery; 3) The pathological diagnoses of GSRCC were confirmed postoperatively; 4) Patients were pathologically at stages II and III after surgery. The exclusion criteria were as follows: 1) Patients with local excision, tumors or lymph nodes biopsy and combined organ resection; 2) Patients with stage I or IV; 3 ) Cases with missing information.

\section{Data collection}

The data collected included: 1) Demographic characteristics including age, gender and race; 2) Pathological characteristics including tumor location, tumor size, depth of infiltration, TNM staging and differentiation grade; 3) Treatment sequences; 4) Follow-up information including outcome, cause of death and survival time. Overall survival (OS) and cancer-specific survival (CSS) were used as prognostic indicators. OS was defined as the duration from the initial diagnosis to any causes of death. CSS was defined as the duration from the initial diagnosis to cancer-related death.

\section{Statistical analysis}

Categorical variables were compared using the $\chi 2$ test or Fisher's exact test. Univariate and multivariate Cox proportional hazard regression models were constructed to explore the associations between clinicopathological characteristics and OS, as well as CSS. All parameters that were statistically 
significant in the univariate analysis were included in the multivariate Cox model. OS and CSS were estimated using the Kaplan-Meier method and differences in survival were examined using the log-rank test.

Propensity Score Matching (PSM) was used to reduce confounding factors. The matching process was conducted with a minimum-distance scoring method and patients with the nearest propensity scores were matched between two groups using a 1:1 scheme. Matching variables included gender, race, age, tumor location, tumor size, depth of infiltration, TNM staging and differentiation grade. The caliper width allowed was 0.05 . Patients without matched observation were excluded. A p-value $<0.05$ was considered statistically significant. PSM was carried out using the "Matchlt" package in statistical software R version 3.6.1 (The R Foundation. Vienna, Austria). All other analyses were performed using IBM SPSS version 21.0 (IBM SPSS, Armonk, NY).

\section{Results}

\section{Clinical and pathological characteristics}

A total of 1413 locally advanced GSRCC patients were included. Patients were divided into three groups based on treatment type: surgery alone (S) group, preoperative radiotherapy + surgery $(R T+S)$ group, and surgery + postoperative radiotherapy (S+RT) group. There were 727 cases in the $S$ group, 138 cases in the RT+S group and 548 cases in the S+RT group. A comparison of the clinicopathological characteristics according to treatment group is detailed in Table 1. Gender, race, age, tumor location and depth of infiltration showed significant differences among the three groups whereas there were no significant differences in TNM staging, differentiation grade and tumor size. 
Table 1

Patient and tumor characteristics compared by treatment type

\begin{tabular}{|c|c|c|c|c|c|}
\hline Characteristics & $S$ & $\mathrm{RT}+\mathrm{S}$ & S+RT & $x^{2}$ & $\mathbf{P}$ \\
\hline & $N=727$ & $N=138$ & $N=548$ & & \\
\hline Race & & & & 36.378 & $<0.0001$ \\
\hline White & $499(68.6)$ & $125(90.6)$ & $353(64.4)$ & & \\
\hline Black & $90(12.4)$ & $8(5.8)$ & $78(14.2)$ & & \\
\hline Others & $138(53.1)$ & $5(3.6)$ & $117(21.4)$ & & \\
\hline Gender & & & & 28.525 & $<0.0001$ \\
\hline Male & $393(54.1)$ & 107 (77.5) & $293(53.5)$ & & \\
\hline Female & $334(45.9)$ & $31(22.5)$ & $255(46.5)$ & & \\
\hline Age (years) & & & & 108.495 & $<0.0001$ \\
\hline$\leq 50$ & $125(17.2)$ & $23(16.7)$ & $145(26.5)$ & & \\
\hline $51 \sim \leq 65$ & $197(27.1)$ & $57(41.3)$ & $220(40.1)$ & & \\
\hline $66 \sim \leq 75$ & 199 (27.4) & $48(34.8)$ & $132(24.1)$ & & \\
\hline$>75$ & $206(28.3)$ & $10(7.2)$ & $51(9.3)$ & & \\
\hline Tumor Site & & & & 281.507 & $<0.0001$ \\
\hline Cardia/fundus & $190(26.1)$ & $129(93.5)$ & $120(21.9)$ & & \\
\hline body & $139(19.1)$ & $2(1.4)$ & $101(18.4)$ & & \\
\hline Antrum/pylorus & 398 (54.7) & $7(5.1)$ & 327 (59.7) & & \\
\hline Tumor grade & & & & 0.762 & 0.683 \\
\hline Moderately/highly & $15(2.1)$ & $4(2.9)$ & $15(2.1)$ & & \\
\hline Poorly & 712 (97.9) & $134(97.1)$ & $533(97.3)$ & & \\
\hline TNM stage & & & & 2.395 & 0.302 \\
\hline II & 303 (41.7) & $60(43.5)$ & $208(38.0)$ & & \\
\hline III & $424(58.3)$ & $78(56.5)$ & $340(62.0)$ & & \\
\hline Depth of infiltration & & & & 33.711 & $<0.0001$ \\
\hline T1 & $19(2.6)$ & $3(2.2)$ & $17(3.1)$ & & \\
\hline T2 & $214(29.4)$ & $43(31.2)$ & $189(34.5)$ & & \\
\hline T3 & $324(44.6)$ & $86(62.3)$ & $232(42.3)$ & & \\
\hline T4 & $170(23.4)$ & $6(4.3)$ & $110(20.1)$ & & \\
\hline Tumor size(mm) & & & & 4.111 & 0.662 \\
\hline$\leq 20$ & $79(10.9)$ & $20(14.5)$ & $57(11.0)$ & & \\
\hline $21 \sim \leq 40$ & $227(31.2)$ & 49 (35.5) & $172(31.4)$ & & \\
\hline $41 \sim \leq 60$ & $198(27.2)$ & $30(21.7)$ & $147(26.8)$ & & \\
\hline$>60$ & $223(30.7)$ & $39(28.3)$ & $172(31.4)$ & & \\
\hline
\end{tabular}

\section{Outcomes before PSM}

The median overall survival time in the S, RT+S and S+RT groups was 19, 26 and 33 months, respectively. The OS rate in the S group (19.5\%) was significantly lower than that in the RT+S $(26.9 \%)$ or the $\mathrm{S}+\mathrm{RT}(34.0 \%)$ group $(p<0.05)$. There was no significant difference in the OS between the $\mathrm{RT}+\mathrm{S}$ group and the S+RT group (Fig. 1A). The median CSS time in the S, RT+S and S+RT groups was 29,31 and 43 months, respectively. The CSS rate in the $\mathrm{S}$ group $(32.4 \%)$ was significantly lower than that in the $\mathrm{S}+\mathrm{RT}$ group $(43.6 \%)(p<0.05)$ but showed no significant difference when compared with the $\mathrm{RT}+\mathrm{S}$ group (35.3\%). There was no significant difference in CSS between the RT+S group and the S+RT group (Fig. 1B). 


\section{Outcomes after PSM}

After covariates were adjusted by PSM, 138 pairs were matched in the $S$ and RT+S groups, 548 pairs in the SA and S+RT groups and 138 pairs in the $\mathrm{RT}+\mathrm{S}$ and S+RT groups. There were no significant differences in clinicopathological characteristics between the two groups (Table 2). The median survival time in the SA and RT+S groups was 19 and 26 months, respectively. The OS rate was $16.5 \%$ in the SA group, which was significantly lower than that of the RT+S group $(26.9 \%, p=0.012)$ (Fig. 2A). Similar results were obtained for CSS $(28.5 \%$ vs. $35.3 \%, p=0.085)($ Fig. $2 B)$. Furthermore, the S+RT group showed a better prognosis than the S group as evidenced by longer OS and CSS (OS, $34.0 \%$ versus $21.1 \%, p<0.0001 ;$ CSS, $43.6 \%$ versus $32.1, p<0.0001$ ) (Fig. 3A, B). The prognosis of the RT+S group and S+RT group was not significantly different with the OS being $26.9 \%$ and $35.7 \%$ respectively ( $p=0.184)$ (Fig. $4 A)$, and the CSS being $35.3 \%$ and 45.8 respectively $(p=0.184)$ (Fig. 4B). 
Table 2

Clinicopathological characteristics after covariates were adjusted by PSM

\begin{tabular}{|c|c|c|c|c|c|c|c|c|c|c|c|c|}
\hline characteristics & SA & $\mathrm{RT}+\mathrm{S}$ & $x^{2}$ & $\mathbf{P}$ & $s$ & $S+R T$ & $x^{2}$ & $\mathbf{P}$ & $\mathrm{RT}+\mathrm{S}$ & S+RT & $x^{2}$ & $\mathbf{P}$ \\
\hline & $N=138$ & $N=138$ & & & $N=548$ & $N=548$ & & & $N=138$ & $N=138$ & & \\
\hline Race & & & 0.063 & 0.969 & & & 0.068 & 0.967 & & & 0.897 & 0.837 \\
\hline \multirow[t]{2}{*}{ White } & 124 & 125 & & & 357 & 353 & & & 108 & 112 & & \\
\hline & (89.9) & $(90.6)$ & & & $(65.1)$ & $(64.4)$ & & & (78.3) & $(81.2)$ & & \\
\hline \multirow[t]{2}{*}{ Black } & 9 & 8 & & & 77 & 78 & & & 13 & 10 & & \\
\hline & $(6.5)$ & $(2.9)$ & & & $(14.1)$ & $(14.2)$ & & & $(9.4)$ & $(7.2)$ & & \\
\hline \multirow[t]{2}{*}{ Others } & 5 & 5 & & & 114 & 117 & & & 17 & 16 & & \\
\hline & (3.3) & $(1.8)$ & & & $(20.8)$ & $(21.4)$ & & & (12.3) & (11.6) & & \\
\hline Gender & & & 1.113 & 0.366 & & & 0.092 & 0.808 & & & 0.181 & 0.777 \\
\hline \multirow[t]{2}{*}{ Male } & 114 & 107 & & & 298 & 293 & & & 104 & 107 & & \\
\hline & $(82.6)$ & $(77.5)$ & & & $(54.4)$ & $(53.5)$ & & & $(75.4)$ & $(77.4)$ & & \\
\hline \multirow[t]{2}{*}{ Female } & 24 & 31 & & & 250 & 255 & & & 34 & 31 & & \\
\hline & $(17.4)$ & $(22.5)$ & & & $(45.6)$ & $(46.5)$ & & & $(24.6)$ & $(22.5)$ & & \\
\hline Age (years) & & & 5.331 & 0.149 & & & 7.510 & 0.057 & & & 7.403 & 0.060 \\
\hline \multirow[t]{2}{*}{$\leq 50$} & 22 & 23 & & & 125 & 145 & & & 38 & 23 & & \\
\hline & $(15.9)$ & $(16.7)$ & & & $(22.8)$ & $(26.5)$ & & & $(27.5)$ & $(16.7)$ & & \\
\hline \multirow[t]{2}{*}{$51 \sim \leq 65$} & 54 & 57 & & & 197 & 220 & & & 58 & 57 & & \\
\hline & $(39.1)$ & $(41.3)$ & & & $(35.9)$ & $(40.1)$ & & & $(42.0)$ & $(41.3)$ & & \\
\hline \multirow[t]{2}{*}{$66 \sim \leq 75$} & 40 & 48 & & & 158 & 132 & & & 31 & 48 & & \\
\hline & $(29)$ & $(34.8)$ & & & $(28.8)$ & $(24.1)$ & & & $(22.5)$ & $(34.8)$ & & \\
\hline \multirow[t]{2}{*}{$>75$} & 22 & 10 & & & 68 & 51 & & & 11 & 10 & & \\
\hline & $(15.9)$ & (31.3) & & & $(12.4)$ & $(9.3)$ & & & $(8.0)$ & $(7.2)$ & & \\
\hline Tumor Site & & & $<0.0001$ & 1.000 & & & 0.257 & 0.879 & & & 9.585 & 0.137 \\
\hline \multirow[t]{2}{*}{ Cardia/fundus } & 129 & 129 & & & 127 & $120(21.9)$ & & & $117(84.8)$ & $120(86.9)$ & & \\
\hline & $(93.5)$ & $(93.5)$ & & & $(23.2)$ & & & & & & & \\
\hline \multirow[t]{2}{*}{ body } & 2 & 2 & & & 99 & 101 & & & 14 & 11 & & \\
\hline & $(1.4)$ & $(1.4)$ & & & $(18.1)$ & $(18.4)$ & & & $(10.1)$ & $(8.0)$ & & \\
\hline \multirow[t]{2}{*}{ Antrum/pylorus } & $7(5.1)$ & $7(5.1)$ & & & 322 & 327 & & & 7 & 7 & & \\
\hline & & & & & $(58.8)$ & $(59.7)$ & & & $(5.1)$ & $(5.1)$ & & \\
\hline Tumor grade & & & $<0.0001$ & 1.000 & & & 0.147 & 0.849 & & & $<0.0001$ & 1.000 \\
\hline \multirow[t]{2}{*}{ Moderately/highly } & 4 & 4 & & & 13 & 15 & & & 4 & 4 & & \\
\hline & $(2.9)$ & $(2.9)$ & & & $(2.4)$ & $(2.7)$ & & & $(2.9)$ & $(1.4)$ & & \\
\hline \multirow[t]{2}{*}{ Poorly } & 134 & 134 & & & 535 & 533 & & & 134 & 134 & & \\
\hline & (97.1) & (97.1) & & & $(97.6)$ & (97.3) & & & (97.1) & (97.1) & & \\
\hline TNM stage & & & 0.132 & 0.809 & & & 0.384 & 0.577 & & & 1.221 & 0.326 \\
\hline \multirow[t]{2}{*}{ II } & 63 & 60 & & & 218 & 208 & & & 51 & 60 & & \\
\hline & $(45.7)$ & $(43.5)$ & & & (39.8) & $(38.0)$ & & & (37.0) & $(43.5)$ & & \\
\hline \multirow[t]{2}{*}{ III } & 75 & 78 & & & 330 & 340 & & & 87 & 78 & & \\
\hline & (54.3) & $(56.5)$ & & & $(60.2)$ & $(62.0)$ & & & $(63.0)$ & $(56.5)$ & & \\
\hline
\end{tabular}




\begin{tabular}{|c|c|c|c|c|c|c|c|c|c|c|c|c|}
\hline characteristics & SA & $\mathrm{RT}+\mathrm{S}$ & $x^{2}$ & $P$ & s & $\mathrm{S}+\mathrm{RT}$ & $x^{2}$ & $\mathbf{P}$ & $\mathrm{RT}+\mathrm{S}$ & $S+R T$ & $x^{2}$ & $\mathbf{P}$ \\
\hline $\begin{array}{l}\text { Depth of } \\
\text { infiltration }\end{array}$ & & & 8.510 & 0.057 & & & 1.341 & 0.719 & & & 0.221 & 0.860 \\
\hline \multirow[t]{2}{*}{ T1 } & 6 & 3 & & & 16 & 17 & & & 5 & 3 & & \\
\hline & $(4.3)$ & (1.1) & & & $(2.9)$ & (3.1) & & & $(3.6)$ & $(2.2)$ & & \\
\hline \multirow[t]{2}{*}{ T2 } & 57 & 43 & & & 172 & 189 & & & 52 & 43 & & \\
\hline & $(41.3)$ & $(31.2)$ & & & $(31.4)$ & $(34.5)$ & & & $(37.7)$ & $(31.2)$ & & \\
\hline \multirow[t]{2}{*}{ Т3 } & 63 & 86 & & & 247 & 232 & & & 60 & 75 & & \\
\hline & $(45.7)$ & $(62.3)$ & & & $(45.1)$ & $(42.3)$ & & & $(43.5)$ & $(54.3)$ & & \\
\hline \multirow[t]{2}{*}{ T4 } & 12 & 6 & & & 113 & 110 & & & 21 & 17 & & \\
\hline & $(8.7)$ & $(4.3)$ & & & (20.6) & $(20.1)$ & & & $(15.2)$ & $(12.3)$ & & \\
\hline Tumor size (mm) & & & 4.740 & 0.192 & & & 0.765 & 0.858 & & & 1.803 & 0.614 \\
\hline \multirow[t]{2}{*}{$\leq 20$} & 16 & 20 & & & 63 & 57 & & & 14 & 20 & & \\
\hline & (11.6) & (14.5) & & & (11.5) & $(10.4)$ & & & $(10.1)$ & $(14.5)$ & & \\
\hline \multirow[t]{2}{*}{$21 \sim \leq 40$} & 41 & 49 & & & 174 & 172 & & & 49 & 49 & & \\
\hline & (29.7) & (35.5) & & & $(31.8)$ & $(31.4)$ & & & $(35.5)$ & $(35.5)$ & & \\
\hline \multirow[t]{2}{*}{$41 \sim \leq 60$} & 46 & 30 & & & 136 & 147 & & & 37 & 30 & & \\
\hline & (33.3) & (21.7) & & & $(24.8)$ & $(26.8)$ & & & (26.8) & $(21.7)$ & & \\
\hline \multirow[t]{2}{*}{$>60$} & 35 & 39 & & & 175 & 172 & & & 38 & 39 & & \\
\hline & (25.4) & (28.3) & & & (31.9) & (31.4) & & & (27.5) & $(28.3)$ & & \\
\hline
\end{tabular}

\section{Prognostic factors for locally advanced GSRCC}

In univariate analysis, age, TNM stage, depth of infiltration, radiotherapy and tumor size were significant prognostic factors for OS and CSS in patients with locally advanced GSRCC. Multivariate analysis identified age, TNM stage, radiotherapy and tumor size as independent prognostic factors for survival (Table 3 and 4).

Table 3

Cox regression analysis of overall survival

\begin{tabular}{|c|c|c|c|c|}
\hline \multirow[t]{2}{*}{ Variables } & \multicolumn{2}{|l|}{ Univariate Cox } & \multicolumn{2}{|l|}{ Multivariate Cox } \\
\hline & $\mathrm{HR}(95 \% \mathrm{Cl})$ & $\mathbf{P}$ & $\mathrm{HR}(95 \% \mathrm{Cl})$ & $\mathbf{P}$ \\
\hline Race (Others/Black/White) & $0.954(0.880 \sim 1.034)$ & 0.252 & - & - \\
\hline Gender (Female/Male) & $0.962(0.846 \sim 1.094)$ & 0.555 & - & - \\
\hline Age $(>75 / 66 \sim \leq 75 / 51 \sim \leq 65 / \leq 50)$ & $1.312(1.231 \sim 1.398)$ & $<0.0001$ & $1.148(1.073 \sim 1.227)$ & $<0.0001$ \\
\hline Tumor Site (Cardiac/Corpus/Antrum) & $1.016(0.945 \sim 1.091)$ & 0.671 & - & - \\
\hline Tumor grade (Poorly/Moderately and highly) & $1.270(0.831 \sim 1.941)$ & 0.269 & - & - \\
\hline TNM site (III/II) & $1.547(1.354 \sim 1.768)$ & $<0.0001$ & $1.452(1.246 \sim 1.691)$ & $<0.0001$ \\
\hline Depth of infiltration (T4/T3/T2/T1) & $1.261(1.158 \sim 1.374)$ & $<0.0001$ & $1.083(0.983 \sim 1.193)$ & 0.107 \\
\hline $\begin{array}{l}\text { Radiotherapy } \\
\text { (Postoperative/Preoperative / without) }\end{array}$ & $0.778(0.727 \sim 0.833)$ & $<0.0001$ & $0.799(0.745 \sim 0.857)$ & $<0.0001$ \\
\hline Tumor size $(>60 / 41 \sim \leq 60 / 21 \sim \leq 40 / \leq 20)$ & $1.203(1.128 \sim 1.284)$ & $<0.0001$ & $1.148(1.073 \sim 1.227)$ & $<0.0001$ \\
\hline
\end{tabular}


Table 4

Cox regression analysis of cancer specific survival

\begin{tabular}{|lllll|}
\hline Variables & \multicolumn{3}{c}{ Univariate Cox } & Multivariate Cox \\
\cline { 2 - 4 } & HR $(95 \% \mathrm{Cl})$ & $\mathrm{P}$ & $\mathrm{HR}(95 \% \mathrm{Cl})$ & $\mathrm{P}$ \\
\hline
\end{tabular}

\begin{tabular}{|c|c|c|c|c|}
\hline Race (Others/Black/White) & $\begin{array}{l}0.979 \\
(0.892 \sim 1.076)\end{array}$ & 0.664 & - & - \\
\hline Gender (Female/Male) & $\begin{array}{l}0.925 \\
(0.796 \sim 1.075)\end{array}$ & 0.311 & - & - \\
\hline $\operatorname{Age}(>75 / 66 \sim \leq 75 / 51 \sim \leq 65 / \leq 50)$ & $\begin{array}{l}1.131 \\
(0.049 \sim 1.219)\end{array}$ & 0.001 & $\begin{array}{l}1.095 \\
(1.016 \sim 1.181)\end{array}$ & 0.018 \\
\hline Tumor Site (Cardiac/Corpus/Antrum) & $\begin{array}{l}0.988 \\
(0.908 \sim 1.074)\end{array}$ & 0.774 & - & - \\
\hline Tumor grade (Poorly/Moderately and highly) & $\begin{array}{l}1.698 \\
(0.958 \sim 3.011)\end{array}$ & 0.070 & - & - \\
\hline TNM site (III/II) & $\begin{array}{l}1.908 \\
(1.623 \sim 2.245)\end{array}$ & $<0.0001$ & $\begin{array}{l}1.710 \\
(1.424 \sim 2.054)\end{array}$ & $<0.0001$ \\
\hline Depth of tumor invasion (T4/T3/T2/T1) & $\begin{array}{l}1.330 \\
(1.203 \sim 1.471)\end{array}$ & $<0.0001$ & $\begin{array}{l}1.091 \\
(0.974 \sim 1.223)\end{array}$ & 0.133 \\
\hline $\begin{array}{l}\text { Radiotherapy (Postoperative/Preoperative } \\
\text { /without) }\end{array}$ & $\begin{array}{l}0.826 \\
(0.762 \sim 0.894)\end{array}$ & $<0.0001$ & $\begin{array}{l}0.817 \\
(0.753 \sim 0.887)\end{array}$ & $<0.0001$ \\
\hline Tumor size $(>60 / 41 \sim \leq 60 / 21 \sim \leq 40 / \leq 20)$ & $\begin{array}{l}1.292 \\
(1.196 \sim 1.396)\end{array}$ & $<0.0001$ & $\begin{array}{l}1.216 \\
(1.123 \sim 1.317)\end{array}$ & $<0.0001$ \\
\hline
\end{tabular}

\section{Discussion}

Based on research conclusions from previous studies, the prognosis of GSRCC remains controversial [8-10]. In early GC, the prognosis of GSRCC is better than that of non-GSRCC; however, in advanced stages, the prognosis of GSRCC is worse than that of non-GSRCC. Several reports have shown that a high risk of lymph node metastasis and early peritoneal dissemination could be associated with a worse prognosis [9, 11], due to CDH1-gene mutations and E-cadherin deficiency [12]. Some studies suggest that GSRCC is insensitive to chemotherapy, neither postoperative nor preoperative chemotherapy improves prognosis $[2,9,11,13,14]$. Several trials such as ARTIST [15] and INT0116 [16] have proven that radiotherapy can improve the prognosis of gastric adenocarcinoma.

However, trials targeting the efficacy of radiotherapy in GSRCC patients are scanty and the specific regimens for GSRCC remain uncertain. A previous study using the same database to extract eligible patients but only compare those with and without preoperative radiotherapy has shown that preoperative radiotherapy is associated with significant survival benefits for the patients with advanced GSRCC [17]. In the present study, we divided the study population and the outcomes into three different groups (surgery alone, surgery+pre-operative radiotherapy and surgery+post-operative radiotherapy) thus giving a broader look on the topic. We found that compared with surgery alone, postoperative radiotherapy may improve the prognosis of GSRCC patients, which is consistent with another previous study based on the SEER database [11]. However, these conclusions remain disputed. Zhu et al [18] reported that adjuvant chemoradiotherapy was associated with poor survival compared with adjuvant chemotherapy in GSRCC patients with D2 gastrectomy, with a median follow-up of 80.5 months and the 3-year OS rate was significantly higher in the chemotherapy group (70.5\% vs. $58.6, H R=0.633, p=0.017)$. Hence, further research should be undertaken to clarify this discrepancy.

Contrary to expectations, we found that preoperative radiotherapy did not improve the CSS compared to surgery alone and that postoperative radiotherapy showed a slightly better prognosis than preoperative radiotherapy. This could be owing to the fact that adjacent organs such as the liver and duodenum can reduce the dosage of radiation on lymph node drainage regions. Another possible explanation is that there is still no comprehensive understanding of lymph node drainage region in GSRCC and target regions of GSRCC have not achieved consensus, which may lead to the inaccuracy of radiotherapy. Currently, most studies do not offer compelling evidence on this issue; therefore, more randomized controlled trials are required in further studies.

Furthermore, using univariate and multivariate analyses, we found that the TNM stage was an independent prognostic factor and depth of infiltration was excluded by multivariate analysis. This result suggested that compared with the T stage, lymph node metastasis was considered to be a significant prognostic factor, which was consistent with conclusions from previous related researches [19, 20]. Besides, tumor size is another important factor affecting prognosis and lymph node metastasis. Jun et al [21] suggested that tumor size over $3.5 \mathrm{~cm}$ was an independent risk factor for GC patients. An et al [22] observed 1043 cases of submucosa infiltration in early GC and found that a tumor diameter over $2 \mathrm{~cm}$ was an independent risk factor for lymph node metastasis. Consistent with these researches, we found that tumor size was also an important prognostic factor in patients with GSRCC. 


\section{Conclusions}

In conclusion, compared with surgery alone, surgery combined with preoperative or postoperative radiotherapy is beneficial to the long-term survival of patients with locally advanced GSRCC. Further exploration is warranted to optimize the application of radiotherapy in GSRCC.

\section{Declarations}

\section{Ethics approval and consent to participate}

The SEER database is an open-access cancer database that contains no identifier and is publicly available. Therefore, this study was exempt from the approval by the Institutional Review Board of the First Affiliated Hospital of Fujian Medical University, and the informed consent was waived.

\section{Consent for publication}

Consent for publication was obtained from all participants.

\section{Availability of data and materials}

Publicly available datasets analyzed were acquired from The Surveillance, Epidemiology, and End Results (SEER) program (https://seer.cancer.gov/).

\section{Competing interests}

The authors declare that they have no competing interests.

\section{Funding}

This work was supported in part by the National Natural Science Foundation of China (81872364).

\section{Authors' contributions}

X.L., Y.H. and J.Y. were involved in study conception and design; X.L., B.C., W.Z., S.Y. and G.Z. collected and analyzed the data; X.L., J.W. and Y.H. wrote the manuscript and interpreted the data; and all authors read and approved the final version of the manuscript.

\section{Acknowledgements}

The authors are grateful to the Surveillance, Epidemiology, and End Results (SEER) database for providing high quality clinical data for this study.

\section{References}

1. Sung H, Ferlay J, Siegel RL, Laversanne M, Soerjomataram I, Jemal A et al. Global Cancer Statistics 2020: GLOBOCAN Estimates of Incidence and Mortality Worldwide for 36 Cancers in 185 Countries. CA Cancer J Clin. 2021;71:209-249.

2. Li Y, Zhu Z, Ma F, Xue L, Tian Y. Gastric Signet Ring Cell Carcinoma: Current Management and Future Challenges. Cancer Manag Res. 2020;12:7973-7981.

3. Machlowska J, Pucułek M, Sitarz M, Terlecki P, Maciejewski R, Sitarz R. State of the art for gastric signet ring cell carcinoma: from classification, prognosis, and genomic characteristics to specified treatments. Cancer Manag Res. 2019;11:2151-2161.

4. Xu Z, Jin Y, Fang X. [Advances in the research of gastric signet ring cell carcinoma]. Zhonghua Wei Chang Wai Ke Za Zhi. 2018;21:1196-1200.

5. Kwon KJ, Shim KN, Song EM, Choi JY, Kim SE, Jung HK et al. Clinicopathological characteristics and prognosis of signet ring cell carcinoma of the stomach. Gastric Cancer. 2014;17:43-53.

6. Liu X, Cai H, Sheng W, Yu L, Long Z, Shi Y et al. Clinicopathological Characteristics and Survival Outcomes of Primary Signet Ring Cell Carcinoma in the Stomach: Retrospective Analysis of Single Center Database. PLoS One. 2015;10:e0144420.

7. Voron T, Messager M, Duhamel A, Lefevre J, Mabrut JY, Goere D et al. Is signet-ring cell carcinoma a specific entity among gastric cancers? Gastric Cancer. 2016;19:1027-1040.

8. Shi T, Song X, Liu Q, Yang Y, Yu L, Liu B et al. Survival benefit of palliative gastrectomy followed by chemotherapy in stage IV gastric signet ring cell carcinoma patients: A large population-based study. Cancer Med. 2019;8:6010-6020.

9. Wei F, Lyu H, Wang S, Chu Y, Chen F. Postoperative Radiotherapy Improves Survival in Gastric Signet-Ring Cell Carcinoma: a SEER Database Analysis. J Gastric Cancer. 2019;19:393-407.

10. Chiu PW, Teoh AY, To KF, Wong SK, Liu SY, Lam CC et al. Endoscopic submucosal dissection (ESD) compared with gastrectomy for treatment of early gastric neoplasia: a retrospective cohort study. Surg Endosc. 2012;26:3584-3591.

11. Piessen G, Messager M, Leteurtre E, Jean-Pierre T, Mariette C. Signet ring cell histology is an independent predictor of poor prognosis in gastric adenocarcinoma regardless of tumoral clinical presentation. Ann Surg. 2009;250:878-887. 
12. Humar B, Blair V, Charlton A, More H, Martin I, Guilford P. E-cadherin deficiency initiates gastric signet-ring cell carcinoma in mice and man. Cancer Res. 2009;69:2050-2056.

13. Messager M, Lefevre JH, Pichot-Delahaye V, Souadka A, Piessen G, Mariette $C$ et al. The impact of perioperative chemotherapy on survival in patients with gastric signet ring cell adenocarcinoma: a multicenter comparative study. Ann Surg. 2011;254:684-693; discussion 693.

14. Piessen G, Messager M, Le Malicot K, Robb WB, Di Fiore F, Guilbert M et al. Phase II/III multicentre randomised controlled trial evaluating a strategy of primary surgery and adjuvant chemotherapy versus peri-operative chemotherapy for resectable gastric signet ring cell adenocarcinomas PRODIGE 19 - FFCD1103 - ADCI002. BMC Cancer. 2013;13:281.

15. Lee J, Lim DH, Kim S, Park SH, Park JO, Park YS et al. Phase III trial comparing capecitabine plus cisplatin versus capecitabine plus cisplatin with concurrent capecitabine radiotherapy in completely resected gastric cancer with D2 lymph node dissection: the ARTIST trial. J Clin Oncol. 2012;30:268-273.

16. Macdonald JS, Smalley SR, Benedetti J, HundahI SA, Estes NC, Stemmermann GN et al. Chemoradiotherapy after surgery compared with surgery alone for adenocarcinoma of the stomach or gastroesophageal junction. N Engl J Med. 2001;345:725-730.

17. Gong H, Chu Y, Hu Q, Song Q. Preoperative Radiotherapy Is Associated With Significant Survival Benefits for Patients With Gastric Signet Ring Cell Carcinoma: A SEER-Based Approach. Technol Cancer Res Treat. 2020;19:1533033820960746.

18. Zhu YT, Chen XZ, Chen Y, Zhou YW, Tang LS, Luo DY et al. Chemoradiotherapy Is Inferior to Chemotherapy Alone in Adjuvant Setting for Signet Ring Cell Containing Gastric Cancer. Front Oncol. 2020;10:570268.

19. Mocellin S. The Effect of Lymph Node Dissection on the Survival of Patients With Operable Gastric Carcinoma. JAMA Oncol. 2016;2:1363-1364.

20. Seevaratnam R, Bocicariu A, Cardoso R, Yohanathan L, Dixon M, Law C et al. How many lymph nodes should be assessed in patients with gastric cancer? A systematic review. Gastric Cancer. 2012;15 Suppl 1:S70-88.

21. Jun KH, Jung H, Baek JM, Chin HM, Park WB. Does tumor size have an impact on gastric cancer? A single institute experience. Langenbecks Arch Surg. 2009;394:631-635.

22. An JY, Baik YH, Choi MG, Noh JH, Sohn TS, Kim S. Predictive factors for lymph node metastasis in early gastric cancer with submucosal invasion: analysis of a single institutional experience. Ann Surg. 2007;246:749-753.

\section{Figures}

$\mathbf{A}$

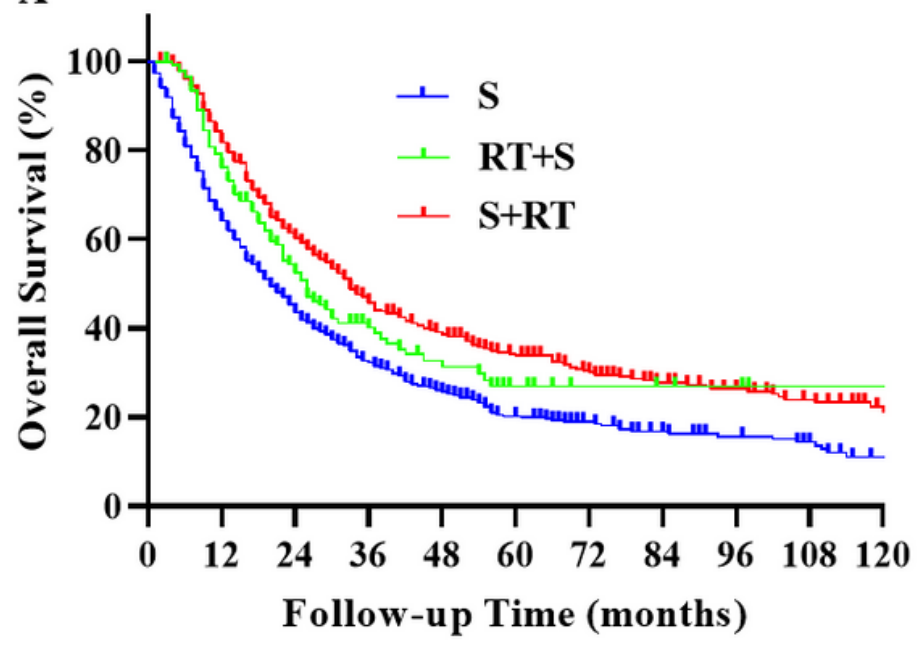

B

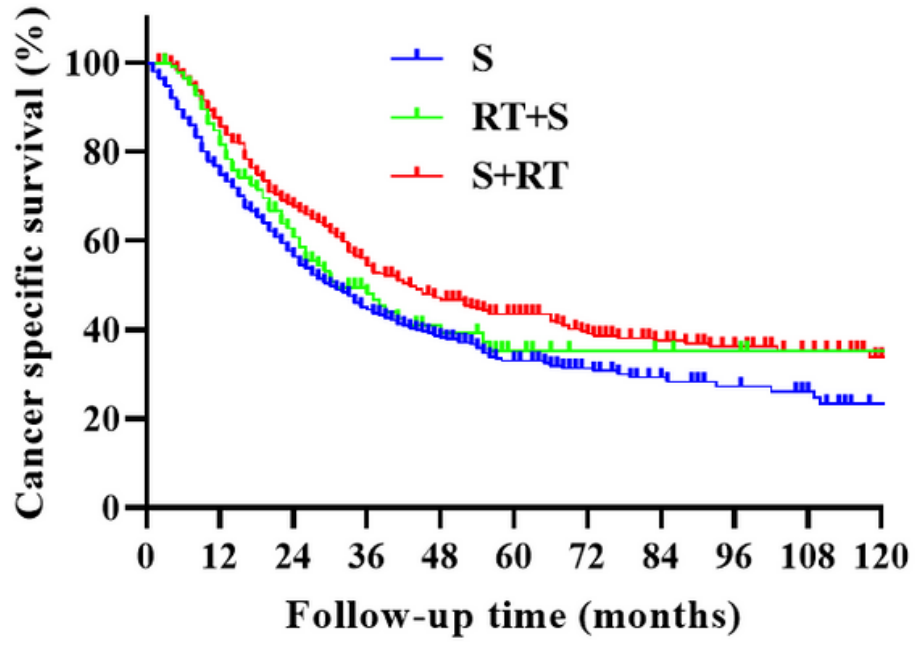

Figure 1

Figure 1

Kaplan-Meier survival curves for overall survival (A) and cancer specific survival (CSS) of the patients with the different treatment types before PSM. 
$\mathbf{A}$

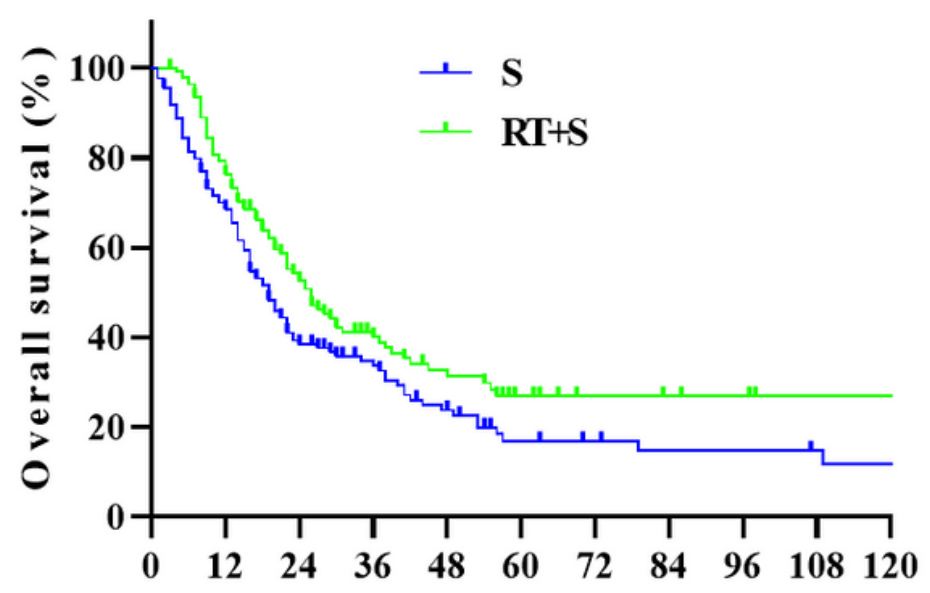

Follow-up time (months)
B

\section{Figure 2}

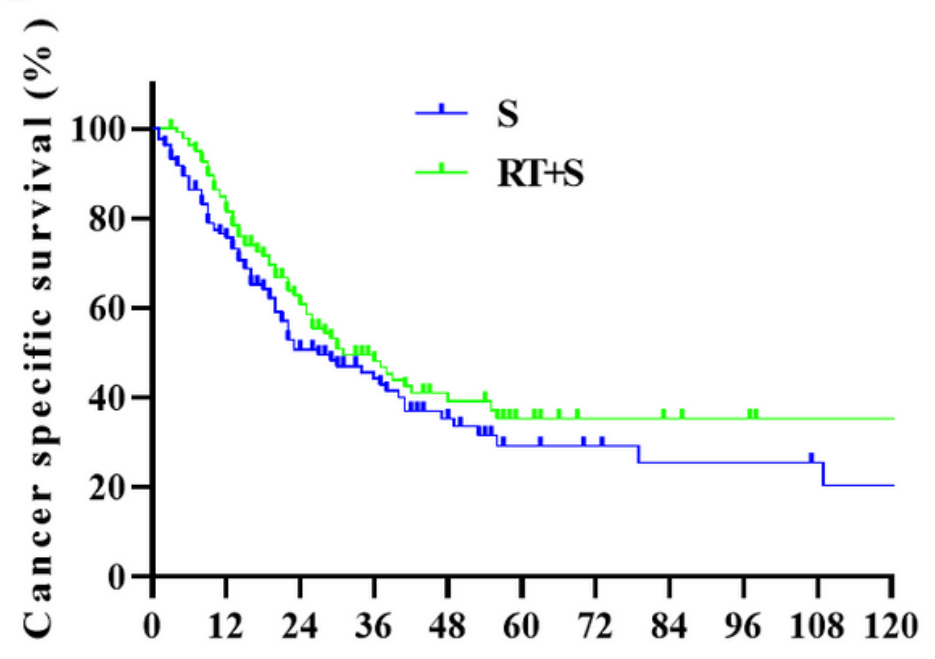

Follow-up time (months)

Figure 2

Kaplan-Meier survival curves for overall survival (A) and cancer specific survival (CSS) of the patients with S or RT+S after PSM.
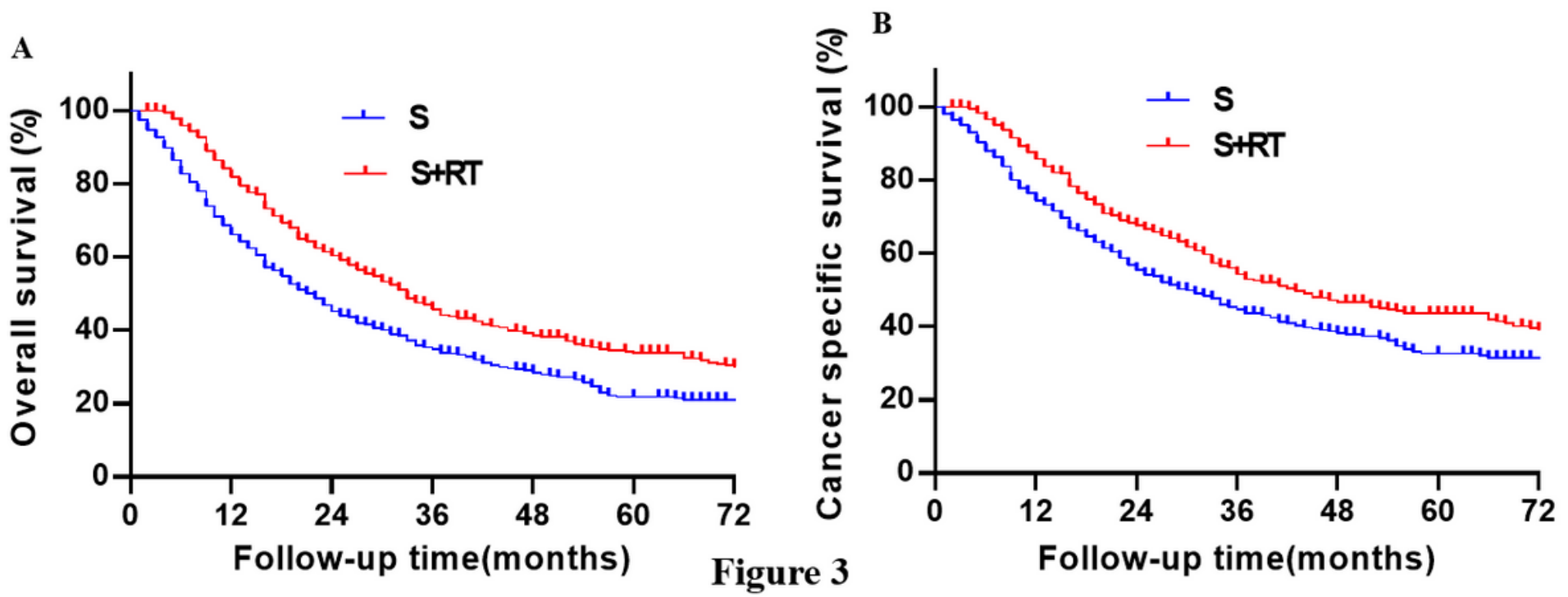

Figure 3

Kaplan-Meier survival curves for overall survival (A) and cancer specific survival (CSS) of the patients with S or S+RT after PSM. 
A

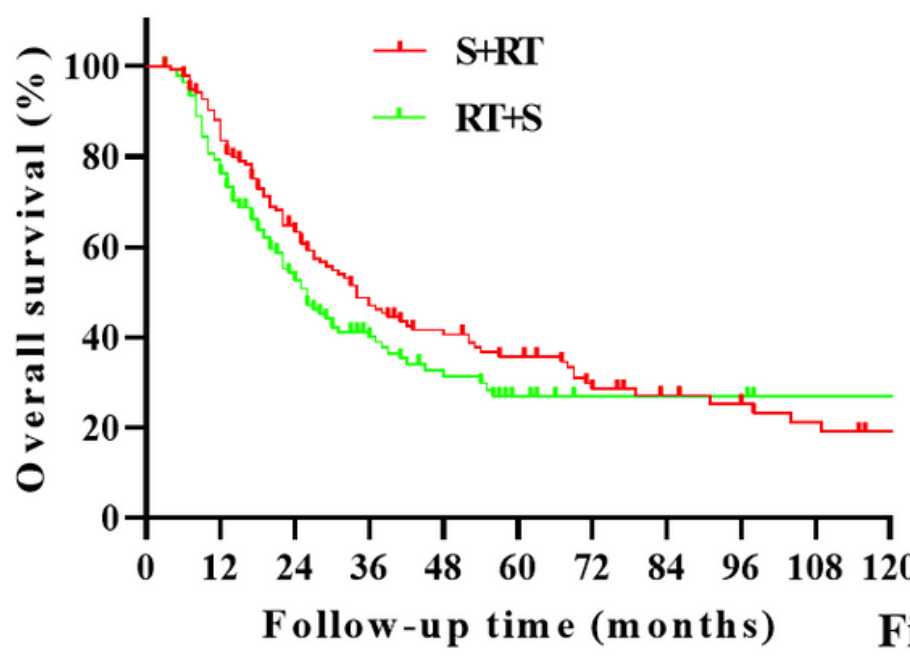

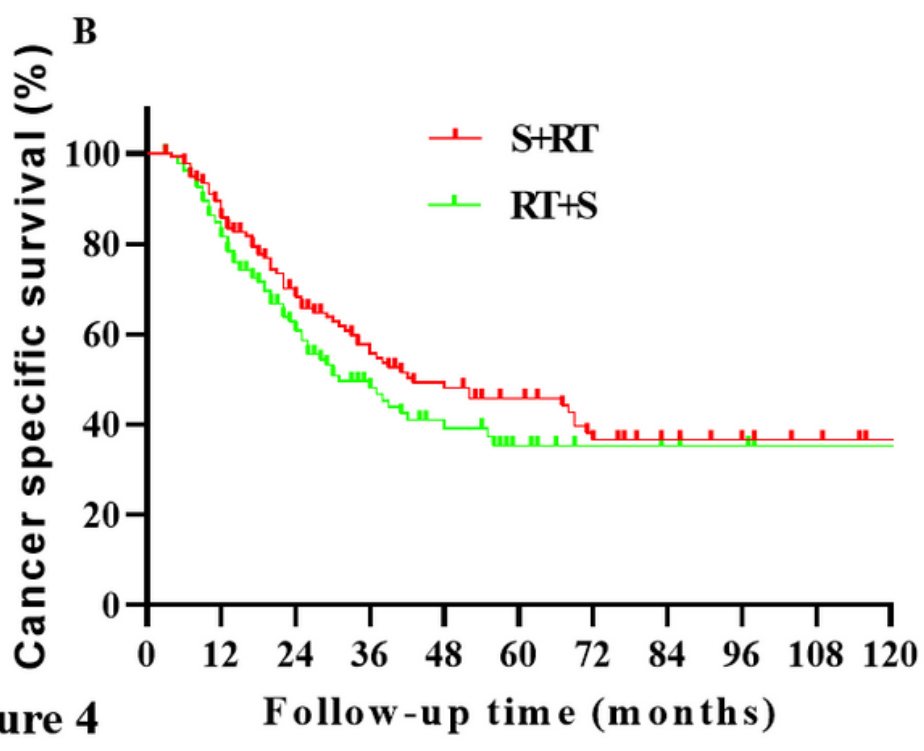

Figure 4 